\title{
Questão do conhecimento - alguns elementos fundamentais
}

\author{
Question of knowledge - some basic elements
}

\author{
Cezar Luis Seibt*
}

Recebido em: 05/2015

Aprovado em: 10/2015

\begin{abstract}
Resumo: $O$ texto indica alguns dos problemas fundamentais do conhecimento, tal como eles se constituem na tradição, desde os gregos. Mostra que as discussões em torno da validade ou não de um conhecimento assentam sobre a dicotomia sujeito $e$ objeto, mente e mundo. Iniciando pelos gregos, enfoca principalmente a forma com Platão desenvolve a reflexão sobre o conhecimento como crença verdadeira justificada, passando pelas teorias sobre as possibilidades e limites elaboradas durante a modernidade. Aponta a dificuldade das teorias enquanto tentativas de superar o abismo que se estabeleceu entre sujeito e objeto, entre mente e o mundo.

Palavras-chave: conhecimento, sujeito e objeto, teorias do conhecimento.
\end{abstract}

Abstract: The text indicates some of the fundamental problems of knowledge, as they are in the tradition, since the Greeks. Shows that the discussions about the validity or otherwise of a knowledge based on the dichotomy subject and object, mind and world. Starting by the Greeks, mainly focuses on the way Plato develops the reflection about knowledge as justified true belief, through the theories about the possibilities and limits developed during modernity. Points out the difficulty of theories as attempts to bridge the gap that was established between subject and object, between mind and world.

Key-words: knowledge, subject and object, theory of knowledge.

*Doutor em Filosofia pela Pontifícia Universidade Católica do RS, Brasil(2009), Professor do Ensino Superior da Universidade Federal do Pará - Campus Cametá, Brasil .

Problemata: R. Intern. Fil. v.6, n. 3(2015), p 336-352 ISSN 2236-8612 doi:HTTP://dx.doi.org/10.7443/problemata.v6i3.24389 


\section{Considerações Introdutórias}

Desde a antiguidade lamenta-se a penúria do conhecimento humano. Os poderes do pensamento e da percepção são limitados, incompletos. Tanto as possibilidades do indivíduo, como também da humanidade como um todo, são fracas. Conhecemos tudo de forma limitada ou condicionada, subjetiva ou relativamente (Cf. SCHNEIDERS, 2007, p. 261). Há empecilhos que atingem o conhecer tanto pelo lado do objeto quanto do sujeito. Essa precariedade já é atestada pela diferença nas posições de Heráclito e Parmênides, além de manifestar-se claramente no ensino dos sofistas.

Vamos procurar indicar alguns dos problemas com que a questão do conhecimento se deparou na tradição. Daremos uma ênfase maior na reflexão desenvolvida por Platão em um de seus textos, tanto pelo fato de que nele aparecem as diferenças que emergiram nos seus antecessores, como também por que nele se anunciam os traços que irão compor o cenário posterior na filosofia.

Evidente é o fato de se descrever o conhecimento como uma relação entre dois elementos, em que um deles apreende o outro, ou que está aberto para o outro. Essa descrição ajuda a conduzir a atenção para alguns elementos fundamentais do conhecimento e para aquilo que possivelmente seja problemático nesta relação. Gabriel afirma que as questões fundamentais da teoria do conhecimento resultam do fato de que "se pergunta pela natureza do sujeito conhecedor, do objeto conhecido e pela relação entre os dois" (in PIEPER, 2004, p. 64). Para Lhano as dificuldades para explicar o conhecimento humano surgem historicamente "de se afirmar uma falta de comunicação e sensibilidade, que procede, por sua vez, da aplicação de um método intuicionista (gnosiologia que propugna um conhecimento direto das essências) e matematizante, como é o de cunho cartesiano" (2004, p. 157). No que se refere às dificuldades da passagem do sensível para o inteligível, do mundo para a mente, diz o mesmo autor que "o empirismo e o racionalismo esbarram em grandes e radicais dificuldades para fundamentar a passagem cognoscitiva do particular sensível para o universal, e para encontrar a realidade concreta correspondente aos conceitos" (LHANO, 2004, p. 157). 
Como se pode verificar, uma das questões importantes com que a filosofia tem se ocupado é a de se o objeto é apreendido efetivamente na sua realidade. Levando essa questão mais adiante, pode-se perguntar pela efetividade mesma do objeto como uma realidade externa ao sujeito. Há um deles (sujeito ou objeto) que determina o outro na relação cognoscitiva? Quem é mais determinante: o sujeito ou o objeto? Há alguma alteração do objeto ou do sujeito na relação cognoscitiva? Como e quando sabemos que um conhecimento é verdadeiro? No conhecimento do objeto a partir do sujeito, o objeto é apreendido na sua essência? Ou somente nas propriedades que aparecem na sua manifestação?

Talvez as duas interrogações fundamentais da teoria do conhecimento sejam as seguintes, tal como formuladas por Chrisholm (1969, p. 80): "O que é que conhecemos?" e "Como decidiremos, em qualquer caso determinado, se sabemos ou não?". Dito de outra maneira, "até que ponto sabemos?" e "Quais são os critérios do conhecimento?". Da resposta a estas indagações surgem posturas determinadas que buscam explicar o fenômeno do conhecimento a partir de um ou outro ponto de vista. O senso comum, o empirismo, o ceticismo, o materialismo, o idealismo ou o racionalismo, cada uma respondeu a seu modo essas perguntas, teve de decidir e separar aquilo que é conhecimento daquilo que não o é, estabelecendo critérios para fazer essa seleção.

Focando o conhecimento nos seus diversos aspectos, constata-se que para cada postura corresponde outra oposta. Temos sempre binômios tais como objetivismo e relativismo, racionalismo e empirismo, realismo e idealismo, dogmatismo e ceticismo, além de outros. Não estamos determinados na escolha, mas num espaço aberto de possibilidades. Temos sempre de procurar razões melhores para a opção que fazemos, para a postura que escolhemos diante do conhecimento.

Se temos de escolher, ponderando melhores razões, isso significa que talvez não estejamos em condições de julgar a verdade a partir de um lugar objetivo, de um lugar absoluto, como se dispuséssemos de um olho divino. Não podemos nos situar fora do horizonte de abertura do mundo, pois somos finitamente constituídos e ocupamos um lugar determinado na história e no espaço. Ou seja, temos de teorizar, construir justificativas e argumentar nossa posição teórica. Normalmente, no entanto, ocultamos esse horizonte de abertura, prévio, 
originário, no qual e a partir do qual escolhemos, argumentamos e, sobretudo, a partir do qual estamos diante de possibilidades, do ser de possibilidade.

Argumentamos, elaboramos critérios, escolhemos. E junto com esses critérios estabelecemos um método específico para acessar a realidade e conhecê-la. Aliás, o método é uma das marcas fundamentais da modernidade e disso nos daremos conta lembrando que Descartes assumiu a dúvida como método radical de investigação do conhecimento. Também o desenvolvimento da ciência moderna foi possível graças à assunção de certos critérios e de uma postura específica em relação ao que é conhecer e não-conhecer, pela opção por um método determinado.

Nota-se que o conhecimento ou as teorias do conhecimento tem a ver com visões antropológicas, com uma imagem de ser humano que sustenta o modo de compreender o processo do conhecer. Isso conduz à necessidade de investigar o próprio ente que conhece. Por exemplo, como sugere Blackburn, podemos "introduzir a visão do homem como um instrumento que recebe inputs/dados e libera outputs/resultados, mas despido de qualquer concepção de sucesso ou fracasso, verdade ou falsidade, correção ou incorreção [...]" (2006, p. 117). Uma visão antropológica tem implicações sobre as concepções do conhecimento.

\section{Conhecimento como 'crença verdadeira justificada'}

Giles (Cf. 1995, p. 58) lembra que Platão se vê confrontado pelo ceticismo e relativismo dos sofistas, tal como foram interpretados por ele. Cada um pode apresentar suas razões e não há nenhum critério objetivo para medir a correção das diversas posições. Isso se expressa bem no ditado de Protágoras, de que 'o homem é a medida de todas as coisas'. Platão se opõe a essa flutuação no conhecimento e apresenta uma norma objetiva e absoluta, que é o mundo das Ideias eternas. Para tanto, precisa postular a existência de dois mundos, sendo um o reino da mudança e o outro da permanência; um é a verdade, a essência, e o outro é a cópia, a sombra. Como o mundo verdadeiro é o mundo das Ideias, o mundo sensível é desprezado, deixado em segundo plano. A ideia existe independentemente do sensível, posição a que Aristóteles se 
opõe: embora a ideia exista, ela não é senão resultado do processo de abstração, que parte do sensível para o inteligível.

O Teeteto de Platão é um dos textos fundamentais na filosofia grega que trata do problema do conhecimento. Nele se descreve como Sócrates, no diálogo com seu interlocutor Teeteto, desloca-se cada vez mais do conhecimento enquanto a enumeração de diferentes disciplinas e artes que se ocupam com ele, para questionar o que seja o conhecimento na sua essência. Não pretende uma enumeração dos conhecimentos particulares disponíveis, mas "a própria essência do gênero que compreende e valida todas as espécies" (NUNES, in Platão, 2001, p. 23). Esse texto representa também uma tentativa de superar as posições céticas e subjetivas dos sofistas, tanto quanto o embate entre Parmênides e Heráclito.

A primeira definição a que o diálogo chega é a de que o "conhecimento não é nada mais do que sensação" (PLATÃO, 2001, p. 49), ideia que caracteriza o pensamento do sofista Protágoras. Mas como para os sentidos nada permanece idêntico e estável, o conhecimento já se torna um problema. Pode-se, na verdade, estar diante de uma aparência e não da realidade. Podese ser vítima de um sonho ou de uma ilusão, tema que será caro a Descartes no início da modernidade.

Essa posição inicial, no entanto, será superada através do movimento dialético do pensamento, próprio dos diálogos platônicos. No decorrer do texto Sócrates discute com os interlocutores temas como a opinião verdadeira e falsa, a unidade e a multiplicidade, a memória como um tipo de conhecimento, a experiência dos sentidos, o raciocínio, e apresenta o raciocínio como o único caminho para se atingir a essência e a verdade, e exclui dessa possibilidade as impressões dos sentidos (Cf. PLATÃO, 2001, p. 102).

Depois se passa a uma segunda formulação do conhecimento, ainda provisória. Há duas espécies de opinião: a verdadeira e a falsa. O conhecimento deve ser "opinião verdadeira" (PLAT ÃO, 2001, p. 103), e não pode ser opinião falsa. Opinião verdadeira é conhecimento e opinião falsa é nãoconhecimento. E o conceito de opinião, aqui importante, é formulado assim:

[...] um discurso que a alma mantém consigo mesma, acerca do que ela quer examinar. [...] é assim que imagino a alma no ato de pensar: formula uma espécie de diálogo para si mesma com perguntas e respostas, ora 
para afirmar ora para negar. Quando emite algum julgamento, seja avançando devagar seja um pouco mais depressa, e nele se fixa sem vacilações: eis o que denominamos opinião. Digo, pois, que formar opinião é discursar, um discurso enunciado, não evidentemente, de viva voz para outrem, porém em silêncio para si mesmo (PLATÃO, 2001, p. 108).

Neste trecho estabelecem-se elementos que irão acompanhar uma das extremidades do pêndulo que, na história do pensamento, se desloca de uma posição para outra antagônica. Nela já se desenha a posição assumida na modernidade a partir de Descartes. O conhecimento como um diálogo interior, que não tem razões para confiar nas impressões dos sentidos e que, por isso, fia-se unicamente em si mesmo.

Mas a definição alcançada até o momento tem um passo a mais para dar. Na seqüência do diálogo, a discussão estabelece mais um detalhe que deverá complementar a definição anterior. Até agora conhecimento é 'opinião verdadeira'. Falta a essa definição a idéia da justificação, pois que "conhecimento é opinião verdadeira acompanhada de explicação racional" (PLATÃO, 2001, p. 125). Conhecimento é opinião verdadeira acompanhada da razão (explicação racional). Essa explicação racional é "tornar claro o pensamento por meio da voz, com o emprego de verbos e substantivos" (PLATÃO, 2001, p. 133).

A justificação racional necessita de articulação num discurso. A justificação se apresenta discursivamente, com palavras e frases. O discurso é o âmbito em que aparece a 'diferença', ou seja, a "explicação racional implica o conhecimento da diferença” (PLATÃO, 2001, p. 139). Desse modo, o conhecimento pode ser agora formulado como "opinião certa aliada ao conhecimento da diferença" (PLATÃO, 2001, p. 140). Ou, como diz Detel, "saber é uma forma da opinião, mas vai para além da mera opinião. Pode-se dizer, por exemplo: 'isso eu não simplesmente acho, isso eu sei'. Deve haver, então, critérios com a ajuda dos quais se possa diferenciar entre mera opinião e saber" (2007, p. 48). Para que uma crença seja confiável é preciso justificá-la de maneira razoável, o que é feito através de razões plausíveis.

Não é difícil notar que no Teeteto aparecem diversos elementos que irão compor as discussões posteriores e marcar inclusive $o$ pensamento atual. A definição tripartite (conhecimento como opinião verdadeira justificada) apresentada 
por Platão é objeto de análise por filósofos contemporâneos. A questão da linguagem ligada ao conhecimento é aqui relevante e não deixou de ser notada por Platão.

Marcante no pensamento platônico é que "a estrutura do conhecimento enquanto episteme principia com as noções comuns - conceitos gerais e categorias, que não devemos à afecção dos sentidos, mas à própria atividade da alma" (NUNES, in Platão, 2001, p. 24). Nesta afirmação estabelece-se uma das tendências fundamentais no desenvolvimento da reflexão sobre o conhecimento: o conhecimento é fruto não da atividade dos sentidos, mas da alma, da razão. Na modernidade isso irá aparecer claramente no racionalismo e idealismo, no sentido de que para eles o mais claro e distinto procede do espírito e não das impressões dadas pelos sentidos (que devem ser postas sob suspeita), e também nos conceitos puros ou categorias a priori de Kant. Não são as coisas que dizem, elas mesmas, quem elas são, mas a atividade da razão é que, enquanto possibilidade do conhecimento, é autora do conhecimento e merece, por isso, ser investigada. A evidência é produzida pela razão e não pela sensibilidade. Conhecimento é, então, aquilo que é evidente. Evidente é o mais razoável, aquilo a que a razão assente. Mas fica também em aberto quais os critérios que estabelecem aquilo que é o evidente ou mais evidente, o razoável ou mais razoável.

Correntemente, como mostra Dancy (Cf. 1985), os trabalhos em torno do problema do conhecimento têm se ocupado desta definição de conhecimento como crença verdadeira justificada. Esta definição tripartida tem merecido a análise, sobretudo, por parte da filosofia da linguagem. O ponto de partida é o conhecimento proposicional, o conhecimento-deque, como no caso de ' $a$ conhece que $p$ '. O conhecimento é proposicional: aquilo que conhecemos é expresso numa proposição, conhecemos algo pela linguagem. A verdade se dá, é possível, na proposição. Como Heidegger afirmou, neste caso 'a proposição é o lugar da verdade' (Cf, 1998, § 44).

Diante daquilo que a proposição enuncia e anuncia, podemos assumir três posições indicadas por Chrisholm (Cf. 1969, p. 37): acreditar e aceitar a proposição, não acreditar e rejeitá-la ou então 'suspender' e abster-se de acreditar. Uma dessas atitudes parecerá mais razoável do que as outras, conduzindo à atitude de aceitação, ou de rejeição ou de abstenção. 


\section{A Possibilidade do conhecimento e as teorias}

Temos então diversas posturas diante do conhecimento. A cada problema foram dadas algumas respostas. Diante da indagação pela possibilidade do conhecimento, surgem algumas possíveis soluções. O mesmo acontece em relação a questão da origem, da essência e da verdade do conhecimento. Lhano esclarece que

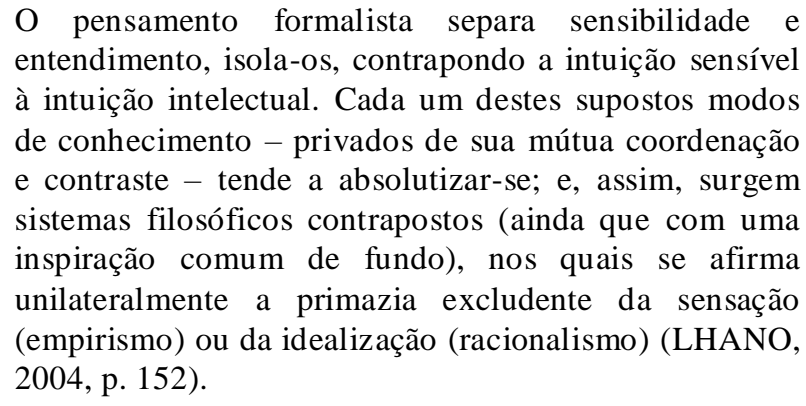

Quanto à possibilidade do conhecimento temos, num dos extremos, a posição cética. O ceticismo é uma das possíveis respostas para a pergunta sobre a possibilidade do conhecimento. É a resposta negativa. Para o cético, as pretensões de conhecimento podem ser postas em dúvida. Mas temos diversos graus de ceticismo que foram sendo formulados ao longo da história, desde os gregos. Há desde o cético que não acredita em conhecimento algum, até aquele que desacredita de algum tipo de conhecimento determinado ou de algum meio determinado de obtenção de conhecimento. Os diversos ceticismos diferenciam-se em função de sua força ou da sua abrangência. O ceticismo forte, como indica Costa (Cf. 2002, p. 67 e 68), coloca em jogo a possibilidade mesma de que se possa ter algum conhecimento, enquanto o fraco duvida de que possamos ter alguma certeza, em algum momento, de que sabemos realmente aquilo que dizemos saber. Quanto à abrangência, ele pode ser total, ou seja, cético em relação à totalidade ou maior parte do conhecimento, ou localizado, quando se refere a uma parte restrita do que conhecemos.

Para Nagel, o ceticismo é a "dúvida radical sobre a possibilidade de chegar a qualquer tipo de conhecimento, liberdade ou verdade ética, dado que estamos contidos no 
mundo e é impossível nos criarmos a nós mesmos a partir do nada" (2004, p. 7). Enquanto dúvida radical, o ceticismo tem um papel importante, visto impedir as conclusões rápidas, os dogmatismos, instigar a investigação e ajudar a esclarecer os problemas em questão.

Do ponto de vista de sua evolução histórica, o ceticismo se desenvolve entre os sofistas gregos, mas é com Pirro de Élis que se torna propriamente uma escola de pensamento. De acordo com Blackburn (Cf. 2006, p. 70 e 71), há certos elementos centrais que se mantêm constantes no ceticismo e que tomaram forma na obra de Sexto Empírico que, por sua vez, sistematiza diversos elementos do pensamento de Pirro. Na descrição realizada por Costa (Cf. 2002, p. 69 e 70), Pirro tem em vista a felicidade do ser humano, a ataraxia, a paz interior.

Vivemos, no entanto, entre alternativas contraditórias indecidíveis, o que torna a busca do conhecimento uma frustração. Não há como escolher e decidir entre alternativas que tem igual peso e "essa constatação de que a busca do conhecimento conduz apenas a contradições insolúveis leva o filósofo à resignação, à desistência, ao que o cético chama de epochê: a suspensão do juízo“ (COSTA, 2002, p. 69). É exatamente aqui, na suspensão do juízo que se encontra a paz interior, a ataraxia buscada. O que temos aqui é, portanto, a constatação da impossibilidade de decidir entre alternativas plausíveis. Isso perturba a pretensão do conhecimento. Provavelmente seja preciso assumir a impossibilidade mesma de decidir, uma resignação que, segundo a argumentação apresentada, tem como conseqüência a paz interior.

Se, como pensa Costa (2002, p. 71), o ceticismo antigo não tem grande valor para nós hoje, a argumentação que se desenvolve na modernidade, motivada principalmente por uma preocupação de cunho epistemológico, representa um desafio para a filosofia atual. Os desafios que os argumentos céticos modernos propõem, evocam respostas novas e criativas, frutos da oposição e contraposição de posições.

Entre as características gerais da argumentação do ceticismo, há algumas constantes, como já dissemos. Blackburn (Cf. 2006, p. 71) considera a centralidade da variação de subjetividades na argumentação cética. Tal argumento tenta mostrar que o conhecimento das coisas varia de acordo com a subjetividade, para sensibilidades diferentes. Não há como decidir se uma percepção é melhor do que a outra e que, por 
isso, é melhor suspender o juízo. Há variação na sensibilidade entre o homem e o animal (variação da percepção animal), entre os próprios seres humanos, entre os sentidos de uma mesma pessoa, as circunstâncias da percepção, as variações que surgem da distância e da perspectiva. Além do mais, há sempre algo mais do que a pura percepção.

O ceticismo é o outro lado da busca do conhecimento objetivo, sua negação, pois o objetivismo tem vocação para sabotar o seu próprio propósito. Por mais que tentemos sair de nós mesmos, da subjetividade para alcançar a objetividade, sempre teremos atrás de nós algum elemento que irá determinar o resultado do conhecimento e que, por isso, colocará em dúvida o acesso ao suposto real. Os conteúdos das crenças não podem facilmente ser defendidos da dúvida. Não podemos sair da nossa concepção de mundo, transformar-nos a tal ponto que possamos estar fora de nós mesmos, em lugar nenhum, como diria Nagel (2004). Estamos sempre num lugar determinado, não transparentes para nós mesmos e "não há meio de mover-nos de onde estamos para chegar a crenças sobre o mundo que sejam substancialmente corretas" (NAGEL, 2004, p. 116). Costa formula esta dúvida cética, a que considera a mais interessante e influente na modernidade, da seguinte forma:

Tudo aquilo a que temos acesso são os conteúdos de nossa consciência: nossos pensamentos, sentimentos, sensações... Ora, se é assim, é falsa a pretensão de conhecermos um mundo exterior, para além dos conteúdos de nossa consciência. Nada garante que o mundo externo não seja muito diverso de como o representamos, ou mesmo que ele realmente exista (COSTA, 2002, p. 72).

Mas passemos para outra posição possível: o perspectivismo. Pode ser apresentado junto ao ceticismo, mas sem ser identificado com ele. $O$ que temos da realidade são diferentes pontos de vista, perspectivas que dependem de fatores relacionados ao objeto, ao sujeito, à própria linguagem, ao contexto temporal e local. Nietzsche tem algo de perspectivista, como mostra Blackburn (Cf. 2006, p. 144). Estamos inevitavelmente presos a perspectivas e, nosso conhecimento, em função disso, só pode ser parcial. Assim, "talvez só haverá versões diferentes, mais ou menos surpreendentes em momentos diferentes, servindo a diferentes propósitos em diferentes climas" (BLACKBURN, 2006, p. 160).

Problemata: R. Intern. Fil. v.6, n. 3(2015), p 336-352 ISSN 2236-8612 
Podemos também considerar que o evento e objeto particular sejam a única realidade efetiva e que, portanto, "a realidade é tão indizivelmente particular que as descrições a falsificam" e, além do mais, temos de desconfiar de que "nossos esquemas classificatórios preferidos sejam adequados à natureza das coisas" (BLACKBURN, 2006, p. 162). O fluxo constante da realidade, já considerado por Heráclito, leva a que se desconfie do conhecimento do universal, de que se possa ter efetivamente conhecimento fora do fluxo dos acontecimentos particulares. "Nossas reações e categorias são impermanentes, as perspectivas mudam e até nossos melhores entendimentos possuem vida finita [...] $\mathrm{O}$ perspectivismo é uma simples conseqüência do heraclitismo", mostra Blackburn (2006, p. 163). A mudança é hostil à tentativa de alcançar um entendimento estável.

Blackburn diz que Aristóteles, ao comentar o Crátilo de Platão, indica que "qualquer uso da língua falsifica a realidade que ela está tentando captar. A realidade escorregadia escapa conforme tentamos mantê-la estável com nossas palavras. Não é possível falar corretamente de qualquer coisa que esteja 'sempre se tornando e nunca é"” (2006, p. 168). A linguagem, para que seja possível, precisa poder encontrar alguma estabilidade em meio à mudança, o mesmo acontecendo com a ciência (não pode haver ciência fora da regularidade, e regularidade exige alguma estabilidade). Alguma perspectiva precisa colocar ordem no movimento, mesmo que com isso não tenhamos nenhuma garantia de que as palavras sejam adequadas às coisas.

Também temos a postura do pragmatismo, que insiste "numa explicação da verdade como nada mais do que verdadecomo-nós-a-medimos ou verdade-para-nós" (BLACKBURN, 2006, p. 92). A verdade depende, neste caso, da finalidade daquilo que se conhece, da sua utilidade para um determinado propósito. Não há verdade em si, independente da vontade ou da intenção daquele que conhece. $\mathrm{O}$ propósito específico deste conhecimento é que servirá de critério de verdade ou falsidade para ele. Dando um exemplo, diz o autor que "não há um único lugar de onde seja correto observar a torre Eiffel e, na verdade, nenhum lugar que seja melhor do que o outro, exceto se for com algum propósito específico" (BLACKBURN, 2006, p. 115).

Já segundo o ponto de vista do dogmático, somos detentores de uma posição que nos permite afirmar absolutamente nosso conhecimento. Há a autoridade do lógos, 
da razão, ou de algum ente transcendente que permite o dogmatismo. Blackburn nota, no entanto, que a pretensão de apreender as coisas como absolutamente certas "parece depender da idéia de uma visão mítica pelo olho de Deus, através da qual saímos da nossa própria pele e fazemos observações de tal extensão que nossa melhor teoria passa a corresponder a uma realidade independente" (BLACKBURN, 2006, p. 101). Em todo caso, o absolutismo depende de algum ponto objetivo, normalmente distinto do sujeito. Já o relativista situa-se na posição oposta, para quem qualquer autoridade é ilusória, e para quem não há ponto de vista divino que possa garantir a verdade. Há ainda outras possíveis posições, mas estas já nos ajudam a verificar a oscilação com a qual nos deparamos.

Enfatizamos a relação sujeito e objeto e algumas posições possíveis quanto a ela. Essa relação, nota Gabriel (Cf. in PIEPER, 2004, p. 63), não pode fácil e simplesmente ser entendida como uma relação empírica na qual se encontram, um diante do outro, elementos empíricos no espaço e no tempo. Há problema quando o sujeito do conhecimento é identificado com o sujeito empírico. Como ele continua dizendo (Cf. in PIEPER, 2004 , p. 64), essa relação entre sujeito e objeto não coincide com a relação entre o cérebro e os objetos físicos. Esse problema leva a que se pergunte, na teoria do conhecimento, fundamentalmente pela natureza do sujeito do conhecimento, do objeto conhecido e da própria relação entre os dois.

\section{Algumas reflexões sobre a modernidade}

Ao longo da história, a preocupação e o foco localizavamse num ou outro extremo desta relação dualista. Podemos dizer que até a modernidade $\mathrm{o}$ foco estava voltado preponderantemente para o objeto. A verdade dependia do objeto, da correspondência e adequação entre o discurso e o objeto. Na modernidade, Descartes começa a deslocar a atenção para o sujeito. Através da aplicação da dúvida metódica ao edifício do conhecimento transmitido pela tradição, afasta-se do objeto para aproximar-se do sujeito. A garantia da existência do mundo externo depende do reconhecimento do sujeito. Este, o sujeito, o 'cogito, ergo sum', torna-se a instância fundante da clareza e evidência do conhecimento. A origem do conhecimento verdadeiro é o sujeito. 
Por outro lado, os empiristas ingleses insistem que a origem se encontra nos sentidos, na experiência. Reedita-se, dessa forma, uma tendência já existente em Platão e Aristóteles de apontar a origem do conhecimento na razão ou nos sentidos. Essas são as duas grandes tendências no que se refere à origem do conhecimento: a razão ou os sentidos. Temos então o racionalismo e o empirismo.

De um lado, Descartes desvaloriza a percepção sensível e toma o conhecimento físico-matemático como modelo e ideal para todo empreendimento filosófico: eis o racionalismo. Por outro, o empirismo se orienta pela percepção e afirma ser a experiência a autêntica fonte do conhecimento: eis o empirismo. A crença comum do cotidiano empírico é de que "as ideias em nossa mente vêm de impressões e as impressões vêm do impacto do mundo sobre nós" (BLACKBURN, 2006, p. 221). Nossa mente, originalmente tabula rasa, é informada pelas informações confiáveis dos sentidos e, portanto, representa o mundo externo. Mas, apesar disso, não é fácil garantir a relação entre a ideia e a coisa.

A filosofia de Descartes, ao postular a separação entre 'res cogitans' e 'res extensa', afirma a separação entre o sujeito e o mundo externo. Um está posto diante do outro. A 'res extensa', o mundo externo, está diante do sujeito 'res cogitans'. Como diz Gabriel, em Descartes "o sujeito e o objeto são substancialmente diferenciados, compreendidos como matéria e espírito" (GABRIEL, in Pieper, 2004, p. 68). O problema agora é como um pode chegar ao outro, como realizar a ponte entre a consciência e o mundo, não só em termos de conhecimento, mas também da ação. Temos, assim, o problema do dualismo corpo e alma, mente e mundo. Como resposta, duas soluções se apresentaram: o materialismo, que afirma que a realidade é material, e o idealismo que, por sua vez, afirma que o real é ideal.

Superando e unificando estas duas tradições do racionalismo e do empirismo Kant produz sua filosofia. A oposição clássica entre racionalismo e empirismo é resolvida no seu criticismo, afirmando que "pensamentos sem conteúdo são vazios, intuições sem conceitos são cegas" (KANT, 1999, p. 92). Blackburn (Cf. 2006, p. 229) afirma que Kant buscava a validade objetiva, uma garantia de que realmente apreendemos as coisas corretamente quando as pensamos. Como não se pode provar que o mundo externo, real, independente da mente deva 
se adaptar ao pensamento, Kant acredita que "pode mostrar que o 'mundo como se apresenta para nós' deve se moldar ao nosso modo de pensar"(BLACKBURN, 2006, p. 229). Nesse caso, "a harmonia entre pensamento e mundo só é garantida porque o mundo sobre o qual pensamos é de alguma forma 'constituído' pelas condições de nosso pensamento e experiência dele" (BLACKBURN, 2006, p. 229).

Resulta para o pensamento moderno, em que o sujeito se afirma para além da dúvida, como no caso de Descartes, o problema da existência do mundo exterior. A questão é como reconquistar este mundo posto em dúvida anteriormente, voltar a poder afirmar a realidade do mundo exterior ao sujeito. Da resposta a esse problema surgem duas alternativas de resposta: o realismo e o idealismo. A primeira reconhece uma realidade externa, independente do fato de haver conhecedor ou não, enquanto que a outra a coloca em dúvida. $\mathrm{O}$ realismo aceita uma realidade externa, mesmo que ela não possa ser conhecida em si mesma, mas somente na sua aparência. O idealismo afirma que quando se vê objetos, temos unicamente a 'impressão de objetos'. Realiza a tentativa de "impedir que a separação entre sujeito e objeto do conhecimento se torne intransponível" (GABRIEL, in Pieper, 2004, p. 68).

O realismo, de acordo com Blackburn, acredita que os comprometimentos

\begin{abstract}
[...] descrevem o mundo; respondem ou representam fatos (independentes) de um tipo específico; há um modo de ser do mundo que os torna verdadeiros ou falsos. Esses fatos são descobertos, não criados e possuem suas próprias naturezas 'ontológicas' e 'metafísicas', sobre as quais a reflexão pode nos informar (2006, p. 189).
\end{abstract}

Estamos postos diante do problema central da filosofia moderna, desde Descartes até Kant, e de uma pluralidade de teorias que procuram oferecer uma solução ao problema e que não alcançaram consenso. É o problema do mundo externo, da realidade objetiva e da sua percepção. Costa descreve e resume assim a origem desse impasse:

Todo conhecimento que temos do mundo físico é adquirido através dos sentidos. Ora, o que os sentidos nos apresentam não pode ser mais do que as nossas próprias sensações, as quais não passam de conteúdos de consciência cuja natureza é mental, interna. Mas, se é 
assim, como é possível que sejamos capazes de adquirir conhecimento de um mundo físico externo? Como é que a mente, só podendo ter acesso a conteúdos mentais, pode conhecer um mundo que lhe é essencialmente heterogêneo? (2002, p. 125).

\section{Considerações finais}

Começamos por tomar o conhecimento como problema, sobretudo na medida em que se constitui de dois polos que, na tradição, foram separados: o sujeito e o objeto. As diversas compreensões do conhecimento (sua origem, tipos, critérios de verdade...) tem a função de construir uma ponte que resolva o problema da separação. Precisam justificar a possibilidade do sujeito alcançar o objeto.

Mostramos, brevemente, como Platão entende o fenômeno do conhecimento como busca superar a opinião, substituindo-a pelo conhecimento, ou seja, pela 'crença verdadeira justificada'. Seu pensamento é inspirador para as soluções posteriores. Na sequência mostramos outras posições epistemológicas: o ceticismo, o perspectivismo, o pragmatismo e o dogmatismo. Indicamos, finalmente, o deslocamento da predominância do foco no objeto para o sujeito, operado na modernidade, a partir de Descartes.

O fato de termos desenvolvido historicamente diversas respostas ao problema do conhecimento nos remete para a complexidade desse fenômeno. Não temos uma única resposta totalmente satisfatória e que tenha se mantido inquestionável. Talvez tenhamos de, em função disso, concluir pela relatividade do conhecimento, se olharmos para as respostas alternativas que o fenômeno recebeu. Relatividade no sentido de que qualquer conhecimento é relativo a uma determinada posição ou condição.

Talvez não sejamos capazes de justificar definitivamente este nosso comportamento. Somos finitos, ou seja, contingentes e sempre situados no mundo, num tempo e lugar. Diante disso somos levados a concluir que nosso conhecer, isso que nos acontece o tempo todo, pois discutimos, falamos, pensamos sobre coisas que dizemos conhecer, não é auto evidente e óbvio. Deveríamos ser levados a realizar uma constante reflexão sobre os limites e possibilidades de nosso conhecer e dos 
conhecimentos que dizemos que temos e adquirimos constantemente.

Uma atitude mais cuidadosa e que busca sempre melhores razões, pode nos livrar da inconsciência dos dogmatismos em diversos graus que tendemos a cultivar. Perguntar e manter sob vigilância $\mathrm{o}$ ato do conhecer pode nos ajudar a entrar num diálogo maior com o mundo, diminuindo o monólogo, que é mais seguro, mas também mais limitador. Pode, inclusive, ampliar a nossa capacidade de escuta e de tolerância, e, ao mesmo tempo, melhorar nossa capacidade argumentativa e nossa disposição para aprender.

Se até hoje não encontramos critérios finais e definitivos, isso pode nos mostrar que o nosso destino é uma busca interminável, mas sempre novamente necessária para não sucumbirmos às ditaduras que se constituem em todos os campos do conhecimento. Pode fazer superar a tendência cotidiana de nos petrificarmos em posições não suficientemente arguidas e testadas, racional e praticamente.

\section{Referências}

BLACKBURN, Simon. Verdade: um guia para perplexos. Rio de Janeiro: Civilização Brasileira, 2006.

CHRISHOLM, Roderick M. Teoria do Conhecimento. Rio de Janeiro: Zahar Editores, 1969.

COSTA, Claudio. Uma introdução contemporânea à filosofia. São Paulo: Martins Fontes, 2002.

DANCY, Jonathan. Epistemologia Contemporânea. Lisboa: Edições 70, 1985.

DETEL, Wolfgang. Erkenntnis- und Wissenschaftstheorie. Stuttgart: Reclam, 2007.

GILES, Th. Ramson. Ramos fundamentais da filosofia: Lógica, Teoria do Conhecimento, Ética e Política. São Paulo: EPU, 1995.

HEIDEGGER. Ser y Tiempo. Chile: Editorial Universitária, 1998.

KANT. Crítica da Razão Pura. São Paulo: Ed. Nova Cultural Ltda, 1999.

LHANO, Alejandro. Gnosiologia Realista. São Paulo: Instituto Brasileiro de Filosofia e Ciência 'Raimundo Lúlio', 2004. 
NAGEL, Thomas. Visão a partir de lugar nenhum. Trad. Silvana Vieira. São Paulo: Martins Fontes, 2004.

PIEPER, Annemarie (org.). Philosophische disziplinen - ein Handbuch. Leipzig: Reclam Verlag, 2004.

PLATÃO. Teeteto - Crátilo. Trad. Carlos A. Nunes. Belém: EDUFPA, 2001.

SCHNEIDERS, Werner. Wieviel Philosophie braucht der Mench? Köln: Anaconda Verlag GmbH, 2007. 